\title{
Clinical findings and genetic analysis of the patients with IL-12Rß1 deficiency from southeast Turkey
}

\author{
Dilek Doğruel1, Özlem Özgür Gündeşlioğlu², Mustafa Yılmaz¹, Derya Alabaz², \\ Derya Ufuk Altıntaş ${ }^{1}$, Emine Kocabaş ${ }^{2}$ \\ Division of ${ }^{1}$ Pediatric Allergy and Immunology and ${ }^{2}$ Pediatric Infectious Diseases, Department of Pediatrics, \\ Cukurova University Faculty of Medicine, Adana, Turkey. E-mail: dilekkaragoz1977@hotmail.com \\ Received: 26th June 2018, Revised: 26th July 2018
}

\begin{abstract}
SUMMARY: Doğruel D, Gündeşlioğlu ÖÖ, Yılmaz M, Alabaz D, Altıntaş DU, Kocabaş E. Clinical findings and genetic analysis of the patients with IL12Rß1 deficiency from southeast Turkey. Turk J Pediatr 2019; 61: 174-179.

IL-12Rß1 deficiency is an autosomal recessive disorder characterized by predisposition to poorly pathogenic mycobacteria, salmonella and candida species. We aimed to analyze the clinical manifestations, immunological and genetic features of IL-12Rß1 deficiency in 10 Turkish patients from a single center. We retrospectively studied the clinical manifestations and genetic analysis of the IL-12Rß1 deficiency patients from 2008 to 2016. Ten patients were diagnosed and followed for eight years. The mean age at onset and diagnosis were 24.1 442.5 (med:10.5) and 52.3 \pm 6.83 (med:20) months, respectively. Parental consanguinity rate was $81.8 \%$. All patients were BCG vaccinated. Abscess and axillary lymphadenopathy in the vaccinated area was the most common initial presentation following the BCG vaccination, six patients had recurring oral candidiasis. Active infections were treated appropriately, in addition to prophylactic therapy with IFNy. We identified 6 different mutations in the IL12RB1 gene in 10 patients including 5 splice-site mutations, 3 missense, 1 frameshift, 1 premature stop codon. One of these mutations was novel. The most common mutation was IVS $8+1 \mathrm{G}>\mathrm{A}(\mathrm{c} .783+1 \mathrm{G}>\mathrm{A})$ followed by p.R175W(c.523C $>\mathrm{T})$. This study emphasizes that patients presented with abscess and axillary lymphadenopathy associated with BCG vaccination should be evaluated for IL-12Rß1 deficiency.
\end{abstract}

Key words: BCG, IL-12Rß1 deficiency, MSMD.

Mendelian susceptibility to mycobacterial infections (MSMD) is an autosomal recessively inherited rare disease. BCGitis due to abscesses at the site of inoculation and regional lymphadenitis following BCG (Bacille CalmetteGuérin) vaccination is a typical presentation of MSMD. Patients are also susceptible to mycobacterium tuberculosis, environmental mycobacteria (EM) and other infectious agents like Salmonella and Candida. ${ }^{1}$ Eleven MSMDcausing genes, including nine autosomal (IFNGR1, IFNGR2, STAT1, IL12B, IL12RB1, ISG15, TYK2, RORC, and IRF8) and two X-linked (NEMO, and CYBB) genes have been discovered so far. ${ }^{2,3}$ Interleukin-12 receptor beta 1 (IL$12 \mathrm{R} \beta 1$ ) deficiency is the most common form of MSMD and comprises about $40 \%$ of cases. ${ }^{4}$

When bacterial phagocytosis occurs, the macrophages secrete IL-12p70, which activates natural killer (NK) and Th1 cells through the IL-12 receptor. This receptor consists of 2 chains, IL12RB1 and IL12RB2. Activation of this complex with the IL-12 ligand promotes phosphorylation and nuclear translocation of the signal transducer and activator of transcription-4 (STAT4), thereby inducing IFN- $\gamma$ production and secretion. Defects in any pathway of the IL-12/IFN- $\gamma$ axis play a role in the pathogenesis of the disease. 5,6

The aim of this study was to summarize the clinical manifestations and genetic analysis of 10 patients with IL-12R $\beta 1$ deficiency in a single tertiary centre from Turkey.

\section{Material and Methods}

\section{Patients}

During 2008-2016, 10 patients from 9 unrelated families who were diagnosed with IL-12R $\beta 1$ 
deficiency were enrolled in this study. All of the patients were diagnosed and followed at Division of Pediatric Allergy and Immunology, Çukurova University Medical Faculty.

Definitive diagnosis of IL-12R $\beta 1$ deficiency was determined when IL12RB1 gene mutation was detected in admitted patients with typical clinical manifestations and/or family history.

The study was approved by the Ethical Committee (2017-68-11) of the institution and signed written informed consents were obtained from all parents.

\section{Data Collection}

The patients' detailed clinical and laboratory data were retrospectively collected from the patients' medical records, including clinical manifestations, age at onset and diagnosis, parental consanguinity, family history, type and severity of infections, lesions induced by inoculation with BCG, immunological laboratory tests, treatments, and outcomes. The severity of the disease was assessed by considering the type of pre-diagnosis infections. The onset age was defined as the age when obvious infections initially occurred. The diagnosis age was accepted as the age when IL12R 31 -related gene mutations were identified. The diagnostic workup also included a complete blood count and blood biochemistry, chest $\mathrm{X}$-rays, thoracic high resolution computerized tomography, and cultures of blood and abscess. All patients received IFN- $\gamma$ replacement therapy at a dose of $50 \mu \mathrm{g} / \mathrm{m}^{2}$ every 2 days.

\section{Immunological Analysis}

Total serum IgG, IgA, and IgM levels were measured by nephelometry (BN ProSpec systems, Date Behring Marburg GmbH, Marburg, Germany). Lymphocyte subsets from peripheral blood were numerated by means of flow cytometry: CD3, CD4, CD8, CD19, CD16-56 (Navios, Beckman Coulter, USA). Laboratory evaluation for neutrophil's oxidative burst was performed by negative nitroblue tetrazolium test.

\section{Genetic Analysis}

Genetic testing to confirm the diagnosis of IL$12 \mathrm{R} \beta 1$ deficiency was done as part of genetic consultation with Medical Genetics Department of Çukurova University Faculty of Medicine. NGS was performed on MiSeq System, Illumina from leukocyte DNA from the cases of IL$12 \mathrm{R} \beta 1$ deficiency patients. In-silico analysis for novel mutations was carried out using SIFT, PolyPhen2 and MutationTaster.

\section{Statistics}

Statistical analysis was performed using the statistical package SPSS software (Version 17.0, SPSS Inc., Chicago, IL, USA). All numerical data are expressed as mean values \pm SD or as proportions.

\section{Results}

Of the 10 patients 7 were female., patients were aged between 18 months to 18 years with a mean age of $6.4 \pm 6.2$ years. The age of onset and the age of diagnosis were $24.1 \pm 42.5$ (med: 10.5) and 52.3 \pm 6.83 (med: 20) months, respectively. The average delay in diagnosis was 2.1 \pm 3.9 (med: 0.6 ) years. All of the patients underwent BCG vaccination at the age of 2 months due to the vaccination program in our country. The period between the BCG vaccination and the development of lymphadenitis ranged from 2 to 22 months. Clinical features of patients are shown in Table I.

The first presentation of 8 patients was axillary lymphadenopathy following the BCG vaccination, with recurrent oral candidiasis in 6 patients. Tuberculous lymphadenitis was detected in seven patients and disseminated tuberculosis in two patients. There was a family history of IL-12R $\beta 1$ deficiency in a patient (P6). This healthy subject was diagnosed with IL-12R $\beta 1$ deficiency by genetic analysis.

Biotinidase deficiency and compound heterozygous mutation [p.D 444H (c.1330G > C)/p. L69Hfs*24(c.196_197dupCATC)] in the BTD gene was detected in one patient (P5). Two patients were accompanied by vasculitis confirmed with skin biopsy (Table I).

IgG, M, A levels, percent lymphocyte subsets were normal in all patients. Neutrophil function tests were detected as $100 \%$ in all patients. Four patients had concomitant salmonella seropositivity. One patient had a positive salmonella blood culture and his clinical manifestations were consistent with typhoid. $M$. tuberculosis complex in 2 patients, M. tuberculosis in 3 patients, $M$. bovis in 2 patients were 


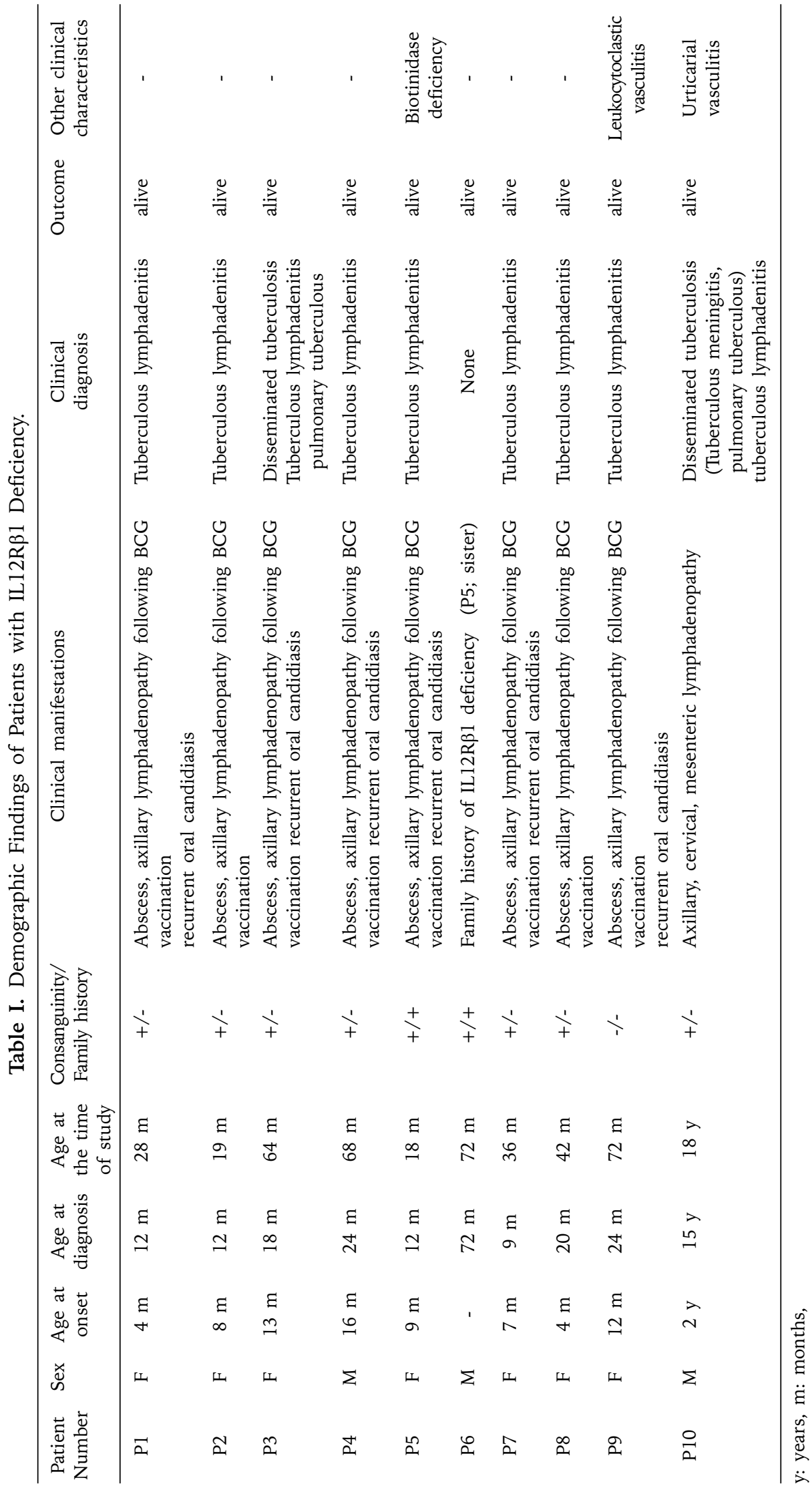


Table II. Genetic Analysis and Laboratory Findings of Patients with IL12R $\beta 1$ Deficiency.

\begin{tabular}{|c|c|c|c|c|c|c|}
\hline No & Genetic defect & $\begin{array}{l}\text { Immunoglobulins } \\
\text { (mg/dl) }\end{array}$ & $\begin{array}{r}\text { Percen } \\
\mathrm{s}\end{array}$ & $\begin{array}{l}\text { t lymphocyte } \\
\text { ubsets }\end{array}$ & Mycobacterium & Salmonellosis \\
\hline 1 & $\begin{array}{l}\text { p.V541Sfs*5(c.1620_162linsA) } \\
\text { Homozygote }\end{array}$ & $\begin{array}{l}G: 1841 \\
M: 258 \\
A: 74\end{array}$ & $\begin{array}{l}\text { CD3:82.3 } \\
\text { CD4:49.1 } \\
\text { CD8:29.2 }\end{array}$ & $\begin{array}{l}\text { CD19:10.1 } \\
\text { CD16-56:3.5 }\end{array}$ & $\begin{array}{l}\text { M. tuberculosis } \\
\text { complex } \\
\text { ARB (+) }\end{array}$ & - \\
\hline 2 & $\begin{array}{l}\text { IVS } 8+1 \mathrm{G}>\mathrm{A}(\mathrm{c} .783+1 \mathrm{G}>\mathrm{A}) \\
\text { Homozygote }\end{array}$ & $\begin{array}{c}\text { G:1199 } \\
\text { M:187 } \\
\text { A:50 }\end{array}$ & $\begin{array}{l}\text { CD3:66 } \\
\text { CD4:44.3 } \\
\text { CD8:20.2 }\end{array}$ & $\begin{array}{l}\text { CD19:26.5 } \\
\text { CD16-56:6.1 }\end{array}$ & - & - \\
\hline 3 & $\begin{array}{l}\text { p.R175W }(c .523 \mathrm{C}>\mathrm{T}) \\
\text { Homozygote }\end{array}$ & $\begin{array}{l}\text { G: } 1292 \\
\text { M:98 } \\
\text { A: } 87\end{array}$ & $\begin{array}{l}\text { CD3:44.2 } \\
\text { CD } 4: 31 \\
\text { CD8: } 14.7\end{array}$ & $\begin{array}{l}\text { CD19:26 } \\
\text { CD16-56:4.9 }\end{array}$ & $\begin{array}{l}\text { M. tuberculosis } \\
\text { and } M . \text { bovis } \\
\text { ARB (+) }\end{array}$ & $\begin{array}{l}\text { Salmonella paratyphi } \mathrm{BH}: 1 / 200 \\
\text { Salmonella paratyphi } \mathrm{BH}: 1 / 400 \\
\text { (Infected with no dinical disease) }\end{array}$ \\
\hline 4 & $\begin{array}{l}\text { p.R213W }(c .637 C>T) \\
\text { Homozygote }\end{array}$ & $\begin{array}{l}\text { G:1048 } \\
M: 79 \\
A: 154\end{array}$ & $\begin{array}{l}\text { CD } 3: 54.2 \\
\text { CD4:42 } \\
\text { CD8:12.7 }\end{array}$ & $\begin{array}{l}\text { CD19:38 } \\
\text { CD16-56:5.9 }\end{array}$ & - & - \\
\hline 5 & $\begin{array}{l}\text { IVS } 8+1 \mathrm{G}>\mathrm{A}(\mathrm{c} .783+1 \mathrm{G}>\mathrm{A}) \\
\text { Homozygote }\end{array}$ & $\begin{array}{l}\text { G:372 } \\
M: 88 \\
\text { A:33 }\end{array}$ & $\begin{array}{l}\text { CD3:65.4 } \\
\text { CD4:46.8 } \\
\text { CD8:17.2 }\end{array}$ & $\begin{array}{l}\text { CD19:26 } \\
\text { CD16-56:4.7 }\end{array}$ & $\begin{array}{l}\text { M Tuberculosis (+) } \\
\text { ARB (+) }\end{array}$ & - \\
\hline 6 & $\begin{array}{l}\text { IVS } 8+1 \mathrm{G}>\mathrm{A}(\mathrm{c} .783+1 \mathrm{G}>\mathrm{A}) \\
\text { Homozygote }\end{array}$ & $\begin{array}{l}\text { G:372 } \\
M: 88 \\
\text { A:33 }\end{array}$ & $\begin{array}{l}\text { CD3:65.4 } \\
\text { CD4:46.8 } \\
\text { CD8:17.2 }\end{array}$ & $\begin{array}{l}\text { CD19:26 } \\
\text { CD16-56:4.7 }\end{array}$ & - & - \\
\hline 7 & $\begin{array}{l}\text { IVS8 }+1 G>A(c .783+1 G>A) \\
\text { Homozygote }\end{array}$ & $\begin{array}{l}\text { G:757 } \\
\text { M:89 } \\
\text { A:62 }\end{array}$ & $\begin{array}{l}\text { CD3:60 } \\
\text { CD4:39 } \\
\text { CD8:23 }\end{array}$ & $\begin{array}{l}\text { CD19:27 } \\
\text { CD16-56:10.9 }\end{array}$ & - & - \\
\hline 8 & $\begin{array}{l}\text { IVS1+2T }>\text { G / IVS8+1G }>\text { A } \\
\text { Combined Heterozygote }\end{array}$ & $\begin{array}{c}\text { G: } 3667 \\
M: 151 \\
\text { A:73 }\end{array}$ & $\begin{array}{l}\text { CD3:64.2 } \\
\text { CD4:49.4 } \\
\text { CD8:12 }\end{array}$ & $\begin{array}{l}\text { CD19:28.5 } \\
\text { CD16-56:4.3 }\end{array}$ & $\begin{array}{l}\text { M. Tuberculosis } \\
\text { Complex } \\
\text { ARB (+) }\end{array}$ & - \\
\hline 9 & $\begin{array}{l}\text { p.R175W }(c .523 \mathrm{C}>\mathrm{T}) \\
\text { Homozygote }\end{array}$ & $\begin{array}{l}\text { G: } 1960 \\
\text { M: } 189 \\
\text { A: } 256\end{array}$ & $\begin{array}{l}\text { CD3:53.5 } \\
\text { CD4: } 31.8 \\
\text { CD8: } 17.8\end{array}$ & $\begin{array}{l}\text { CD19: } 23.6 \\
\text { CD16-56:16.5 }\end{array}$ & $\begin{array}{c}\text { M Bovis (+) } \\
\text { ARB (+) }\end{array}$ & $\begin{array}{c}\text { S. typhimirium } \\
\text { S. typhi } \mathrm{TO}: 1 / 320 \\
\text { S. typhi } \mathrm{TH}: 1 / 20 \\
\text { (Infected with no clinical disease) }\end{array}$ \\
\hline 10 & $\begin{array}{l}\text { p.C } 87^{*}(c .261 \mathrm{C}>\mathrm{A}) \\
\text { Homozygote }\end{array}$ & $\begin{array}{l}\text { G:947 } \\
\text { M:86 } \\
\text { A:519 }\end{array}$ & $\begin{array}{l}\text { CD3:50.7 } \\
\text { CD4:11.1 } \\
\text { CD8:39 }\end{array}$ & $\begin{array}{l}\text { CD19:10.4 } \\
\text { CD16-56: } 19.6\end{array}$ & $\begin{array}{l}\text { M Tuberculosis } \\
(+)\end{array}$ & $\begin{array}{l}\text { S. typhi TO: } 1 / 640 \\
\text { S. typhi } \mathrm{TH}: 1 / 320 \\
\text { (typhoid fever) }\end{array}$ \\
\hline
\end{tabular}

ARB: Acid-Resistant Bacilli

isolated (Table II). These patients were given specific antimicrobial treatment accompanied with IFN-y during severe infection episodes.

Nine of the IL12R $\beta 1$ gene mutations determined in patients were previously identified, 1 of which was a previously unidentified mutation (Fig. 1) (P5).

Four types of mutations were detected: splice site $(n=5)$, missense $(n=3)$, premature stop codon $(n=1)$ and frameshift mutation $(n=1)$. Ten patients had 6 different mutations, the most common mutation was IVS8 $+1 \mathrm{G}>\mathrm{A}(\mathrm{c} .783+1 \mathrm{G}>\mathrm{A}) \quad(\mathrm{n}=4)$ followed by p.R175W $($ c.523C $>$ T) $\quad(n=2) \quad($ Table II $)$.

\section{Discussion}

In this study, we reviewed the clinical and genetic characteristics of patients diagnosed with IL-12R $\beta 1$ deficiency from Çukurova University Faculty of Medicine Children's Allergy Immunology Clinic. All the patients included in the study were living in the southern region of Turkey.

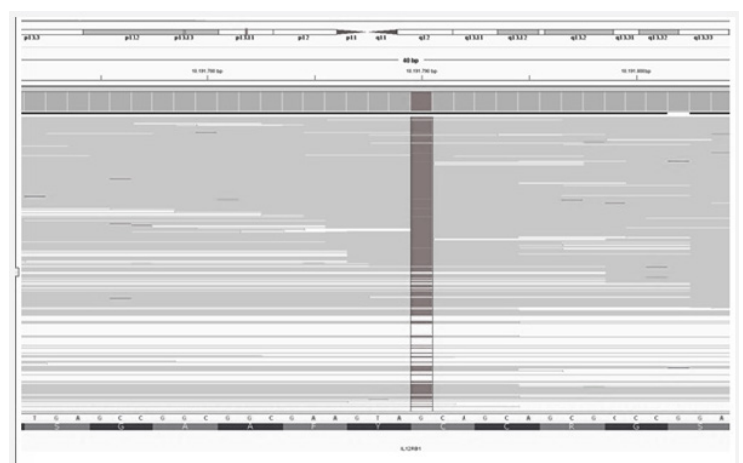

Fig. 1. The novel mutation of the patient via shown by Integrative Genomics Viewer (IGV). 
Although IFN- $\gamma \mathrm{R} 1$ deficiency was the first genetic defect to be identified in MSMD, IL$12 \mathrm{R} \beta 1$ deficiency is the most common defect responsible for MSMD. ${ }^{7}$ In Turkish patients due to the common practice of consanguineous marriages a higher percentage of autosomal recessive forms of immune deficiency are observed. The largest study in the literature is the study of 141 patients from 30 countries, in which the Turkish patients constitute $26 \%$ of the group. ${ }^{8}$

All of our patients were BCG-vaccinated. Of the 10 patients 8 presented with axillary lymphadenopathy following their $B C G$ vaccination. The BCG vaccine is part of the routine vaccination program of our country. ${ }^{9}$ Patients with IL-12R $\beta 1$ deficiency are susceptible to infections caused by weakly virulent mycobacteria such as the BCG vaccine and EM. ${ }^{6}$ Many studies report that the most common infection found in patients with IL$12 \mathrm{R} \beta 1$ deficiency continues to be $M$. bovis $B C G$ disseminated disease due to $85 \%$ vaccination coverage worldwide. On the other hand, it is well-recognized that IL-12R $\beta 1$ deficiency-related $M$. tuberculosis diseases have only been seen in a small number of patients. Interestingly, we isolated M. tuberculosis in 5 of our patients. In addition, the first presentation of 2 patients was disseminated tuberculosis, which rates were significantly higher than those reported in the literature. ${ }^{8}$ Our results, which conflict with the literature, can be explained with the earlier and frequent exposure of patients to M.tuberculosis due to the high prevalence of tuberculosis infection in our country.

Our results suggest that IL-12R $\beta 1$ deficiency should be investigated for patients with unusually severe tuberculosis, even in countries where tuberculosis is prevalent. This is also important for the prognosis of the disease, because recombinant IFN- $\gamma$ is an effective treatment for mycobacterial diseases in patients with IL-12R $\beta 1$ deficiency displaying defective IFN- $\gamma$ production. ${ }^{10}$

Clinical features of IL-12R $\beta 1$-deficient patients are not solely limited to an increased susceptibility to mycobacterial infections. Salmonellosis is the second most common infection in these patients and is reported in about half of the patients. ${ }^{11}$ Although isolated salmonellosis has been reported in the literature, all our patients with salmonella seropositivity were accompanied by myobacteriosis. The use of broad spectrum antibiotics for treatment due to the concomitant mycobacterial infection in patients, may have led to underdiagnosis of Salmonella infections. It is interesting that serological testing detected Salmonella in two of our patients without evidence of clinical disease, which means that at least some IL12R $\beta 1$-deficient patients may be resistant to Salmonella infections (i.e., infected with no clinical disease). ${ }^{12}$ Typhoid fever which is rarely reported in the literature was detected in a patient (P10), caused by S. typhi. ${ }^{8}$

Recurrent oral candidiasis is another clinical manifestation reported in IL-12R $\beta 1$-deficient patients. ${ }^{3}$ Candida is the most common form of infections and it may occur before BCG infection. ${ }^{13}$ Although disseminated fungal infections such as histoplasmosis and paracoccidioidomycosis are rarely observed, mucocutaneous candidiasis is reported in the literature to accompany $25 \%$ of symptomatic patients. ${ }^{8}$ Although, none of our patients experienced invasive candidiasis, six patients had recurrent oral candidiasis.

In the literature, vasculitic skin symptoms are reported in patients with MSMD. ${ }^{14}$ In a study by Beaucoudrey et al. ${ }^{8}$, vasculitis was reported in 3 of 141 patients. In these patients, vasculitic skin symptoms were thought to be secondary to antigenic overload or defective immunomodulatory elimination due to infectious agents. In 2 of our cases, vasculitis symptoms determined by histological examination regressed with antimycobacterial treatment which brought to mind that this condition could be due to secondary infections.

So far, 70 different pathogenic IL12RB1 gene mutations have been identified since it was first reported in 1998. Although the distribution of these mutations worldwide is uneven, c.1791 $+2 \mathrm{~T}>\mathrm{G}$, the most common mutation, was not detected in our patients. ${ }^{2}$ However, the frequency of c.783 + 1G>A and c.523C> $\mathrm{T}$ mutations detected in our patients was similar to the results of a previous study reported from Turkey. ${ }^{1}$ This result suggests that mutation distributions among populations may be relevant to different ethnicity. ${ }^{2}$ In addition, we have detected a novel mutation of c.261C>A which was not previously 
reported. Rarely, detecting IL12RB1 on the cell surface, identifying IL-12R $\beta 1$ deficiency, and the disease manifesting with different genetic defects requires mutation analysis for diagnosis in patients with features that strongly suggest the disease.

In conclusion, in countries where BCG vaccination is routinely performed, patients with BCG related infections should be primarily evaluated for IL-12R $\beta 1$ deficiency which is the most frequent defect that can cause MSMD. In addition, in our country where primary immunodeficiencies are commonly seen, patients with Salmonella seropositivity and recurrent oral candidiasis should also be investigated for IL-12R $\beta 1$ deficiency. Molecular analysis of the IL12RB1 gene is an enabling tool for the diagnosis of IL-12R $\beta 1$ deficiency and is important for genetic counseling.

\section{Acknowledgements}

We would like to thank A. Bisgin, from the Department of Medical Genetics, Çukurova University Hospital for the genetic analysis carried out in the study.

\section{REFERENCES}

1. Tan Ç, Çağdaş-Ayvaz D, Metin A, Keskin Ö, Tezcan İ, Sanal Ö. Clinical and genetic features of IL12Rb1 deficiency: Single center experience of 18 patients. Turk J Pediatr 2016; 58: 356-361.

2. Picard C, Al-Herz W, Bousfiha A, et al. Primary Immunodeficiency Diseases: an Update on the Classification from the International Union of Immunological Societies Expert Committee for Primary Immunodeficiency 2015. J Clin Immunol 2015; 35: 696-726.

3. van de Vosse E, Haverkamp MH, Ramirez-Alejo N, et al. IL-12R $\beta 1$ deficiency: mutation update and description of the IL12RB1 variation database. Hum Mutat 2013; 34: 1329-1339.
4. Aytekin C, Dogu F, Tuygun N, et al. BCG lymphadenitis and recurrent oral candidiasis in an infant with a new mutation leading to interleukin-12 receptor beta-1 deficiency. J Investig Allergol Clin Immunol 2011; 21: 401-404.

5. Al-Muhsen S, Casanova JL. The genetic heterogeneity of mendelian susceptibility to mycobacterial diseases. J Allergy Clin Immunol 2008; 122: 1043-1051.

6. Göktürk B, Reisli İ, Çalışkan Ü, et al. Infectious diseases, autoimmunity and midline defect in a patient with a novel bi-allelic mutation in IL12RB1 gene. Turk J Pediatr 2016; 58: 331-336.

7. Bustamante J, Boisson-Dupuis S, Abel L, Casanova JL. Mendelian susceptibility to mycobacterial disease: genetic, immunological, and clinical features of inborn errors of IFN- $\gamma$ immunity. Semin Immunol 2014; 26 : 454-470.

8. de Beaucoudrey L, Samarina A, Bustamante J, et al. Revisiting human IL-12R $\beta 1$ deficiency: a survey of 141 patients from 30 countries. Medicine (Baltimore) 2010; 89: 381-402.

9. Pala K, Gerçek H, Taş TA, Çakir R, Özgüç S, Yildiz T. 30 years retrospective review of tuberculosis cases in a tuberculosis dispensary in Bursa/Nilufer, Turkey (1985-2014): Changes of epidemics. Mediterr J Hematol Infect Dis 2016; 8: e2016059.

10. Arias AA, Perez-Velez CM, Orrego JC, et al. Severe enteropathy and hypogammaglobulinemia complicating refractory mycobacterium tuberculosis complex disseminated disease in a child with IL-12R $\beta 1$ deficiency. J Clin Immunol 2017; 37: 732-738.

11. Sanal O, Turul T, De Boer T, et al. Presentation of interleukin-12/-23 receptor betal deficiency with various clinical symptoms of Salmonella infections. J Clin Immunol 2006; 26: 1-6.

12. Caragol I, Raspall M, Fieschi C, et al. Clinical tuberculosis in 2 of 3 siblings with interleukin-12 receptor betal deficiency. Clin Infect Dis 2003; 37: 302-306.

13. Ouederni M, Sanal O, Ikinciogullari A, et al. Clinical features of Candidiasis in patients with inherited interleukin 12 receptor $\beta 1$ deficiency. Clin Infect Dis 2014; 58: 204-213.

14. Filiz S, Kocacik Uygun DF, Verhard EM; et al. Cutaneous leukocytoclastic vasculitis due to Salmonella enteritidis in a child with interleukin-12 receptor beta-1 deficiency. Pediatr Dermatol 2014; 31: 236-240. 